2004, 20(3), 316-336

\title{
E-learning compared with face to face: Differences in the academic achievement of postgraduate business students
}

Richard K. Ladyshewsky

Curtin University of Technology

The use of information technology in higher education has increased significantly over the years. There is a paucity of controlled research which examines differences in electronic learning (EL) and face to face (F2F) learning. This study examined student $(\mathrm{n}=1401)$ performance (final grade) in nine units offered in both F2F and EL mode over the course of two years. The effect of age and gender was also considered. Students, on average, did better in the EL mode although at the individual unit level there were minimal if any significant differences. Age and gender did not appear to moderate performance in any way except for those students under 33 who did better, on average, in the EL mode. The implications for teaching and learning in virtual mediums are discussed.

\section{Introduction}

The increasing use of information technology in higher education has seen monumental growth in the past 10 years (Allen, 1999). Halsne \& Gatta (2002) note that distance learning, with its attendant technology, is the fastest growing educational modality. Business education has also been influenced by the growth of information technology as business people often require more flexible access to learning, given their work and travel schedules (Berger 1999; Bull, Kimball \& Stansberry 1998). Understandably, the growth of e-learning (EL) has come under increasing scrutinisation even though traditional face to face (F2F) lecturing has often failed to engage students in the learning process (Alavi 1994). To make comparisons between these two methods of educational delivery is fraught with difficulty. Advocates of EL recognise that it is difficult to make blanket comparisons between these two modes of learning. Both modes are different and distinct in their methods of delivery, even though, the content within them may be the same. 
This paper reviews some of the literature on EL, in particular, where comparisons have been made with F2F lecturing. This is followed by a description of the methodology used to investigate differences in EL and F2F education in a postgraduate business course.

\section{Literature review}

To date, much of the research on EL has focussed on the Internet as an exciting form of technology that can support learning rather than focussing on whether it actually enhances the learning process itself (Sweeney \& Ingram 2001). Further research is needed to determine whether EL is an effective and appropriate method for educational delivery (Arbaugh 2000). Unfortunately, research in this area is often difficult to control given that there are often different variables influencing the educational outcome. For example, the course design (e.g. web supplemented or completely online), the technological applications, pedagogical approaches, student and instructor characteristics, and methods of assessment are all variables (Volery \& Lord, 1999).

It has also been raised whether one should even focus on academic outcomes in EL without considering other social and psychological aspects of the education process (Sweeney \& Ingram 2001). McGrath (1997-98), for example, argues that students who excel in a F2F environment may do less well in EL and vice versa. Further, McGrath noted greater inquisitiveness, expressiveness, risk taking, decreased inhibition, reduction of gender barriers, and increased social connectedness as a result of electronic conferencing. Similar findings are paralleled by Hiltz (1986), who argues that the written word allows students to be freer in their expression and that asynchronous online discussion increases the effectiveness of learning. The role of the instructor is also different in EL with students becoming more active participants in the construction of knowledge and meaning (McGrath, 1997-98). Clearly there are numerous factors that influence success in teaching and learning online.

The focus on outcomes, other than academic grades, is also highlighted in a review of the online collaborative learning literature by Treleaven (2003). In this review, Treleaven notes the importance of the social context in learning by citing phenomenological and ethnographic studies that have examined learning outcomes in online education. These studies have examined online learning from the perspective of students' perceptions and experiences, the instructional methodology used to achieve outcomes and the socio-cultural phenomena that support socially constructed learning and meaning. 
While the merits of phenomenological and ethnographic research on student learning in online settings are important, controlled research that evaluates performance outcomes across delivery methods (i.e. face to face and online) is similarly important.

\section{Pedagogical issues}

Much of the criticism of EL stems from the inappropriate use of this technology to support learning. Educational programs that have merely posted material onto the web and called it EL have been the centre of this criticism. A high quality EL experience requires a pedagogical approach that creates a responsive and creative learning environment. Research by Mioduser, Nachmias, Lahav \& Orens (2000), for example, and their analysis of 436 randomly chosen educational websites, found that in relation to pedagogy most of these online courses reflected traditional approaches commonly found in text books and $\mathrm{CD}$ multimedia. They found that most sites promoted individual rather than collaborative learning; direct instruction rather than inquiry; clicking rather than communicating; automatic feedback rather than guidance; and memorisation instead of knowledge construction.

To ensure that there is a pedagogical focus to a unit that is offered in technologically supported learning environments, a variety of principles espoused by Chickering and Erhmann (1996) should be followed. These principles include: student-teacher contact (email and bulletin boards); active learning techniques (problem solving, inquiry and project based tasks); prompt feedback (person to person and within group); communication of high expectations (making criteria and learning outcomes explicit); time on task (fostering awareness of time constraints and making contributions relevant); respect for diverse learning communities (learners given freedom to control and explore); and reciprocity and collaboration among students (collaboration, peer learning and assessment). Hence, a well constructed EL unit must have a clear and transparent pathway for the learner. The unit material that is available online must be integrated in a way that make sense to the learner. Online activities, assignments and exercises must also be aligned with assessment to encourage learner engagement. Academic faculty must participate in the EL unit by receiving and answering emails and by being involved in synchronous or asynchronous discussions. By following these pedagogical strategies, more positive educational outcomes for the learners are likely to surface. Hence, criticism of EL as a method of educational delivery must look beyond the technology and instead, consider the pedagogical initiatives that have been factored into the design and delivery of the EL experience. 
Arbaugh (2000) for example, in a review of the literature, supports the need for a strategic pedagogical focus in EL by noting that course design and the use of collaborative learning strategies have a profound influence on EL outcomes. Arbaugh (2000) further argues that class size is another important factor in the success of EL. Smaller class sizes facilitate integration and the development of community and are more manageable by students and staff. This is often in direct contrast to institutional views that EL can facilitate mass education with little staff input. Other factors that are important for the construction of an EL unit that have been noted by McLoughlin (2000) include:

- understanding the processes of EL: recognising that learners choose the time, place and resources to support their learning;

- that information technology should be used to increase human

interaction rather than for providing print material;

- that learning is ongoing and is both formal and informal; that design is process based and learner centred;

- that learning activities must be planned to engage learners in an experiential manner; and

- that staff support learning and offer multiple perspectives rather than delivering content.

The importance of pedagogical input into the design and delivery of EL is best put forward by Jasinski (1998 p.1):

Technology does not cause learning. As an instructional medium, online technologies will not in themselves improve or cause changes in learning. What improves learning is well-designed instruction. Online learning environments have many capabilities and the potential to widen options and opportunities available to teachers and learners. Technology is coming before pedagogy.... at this stage of development, the effort put into exploring technologies to 'keep the cutting edge' is at the expense of equal investment in the underpinning of educational design.

\section{Comparisons between EL and F2F teaching}

While there has been some research comparing F2F and EL directly, these are few in number. The most significant results from good research in this area indicate that outcomes achieved using technology are at least the same as for those in traditional settings (Brennan, McFadden \& Law 2001). although several of the studies that are described in this section illustrate enhanced learning outcomes with the use of computer mediated learning.

In one study of undergraduate marketing students, Sweeney \& Ingram (2001) evaluated learning preferences for tutorials offered in F2F versus the web (asynchronous and synchronous). While web based approaches were seen as more innovative and enjoyable, the F2F tutorials were seen as 
more effective learning environments by the students. Gender and Internet experience did not seem to influence perceptions of the different tutorial types, but ethnicity did. In particular, Asian students were more positive with respect to Web based approaches and felt that they had participated more fully in the electronic medium. Web based environments were also perceived by the students to have a greater sense of sharing and equality and were more collaborative. It is important to note in this study, however, that nearly all students were under 25 and full time. Preference for F2F stemmed from the opportunity for greater interaction with the tutor and the possibility of getting direct information on 'right and wrong' answers. Hence, surface approaches to learning, evident in the learners' behaviour in this study, may have driven preferences towards F2F methods.

In another study, Alavi (1994) compared the performance of a group of Master of Business Administration students in an information systems unit who used computer based group decision support software, as part of a collaborative learning exercise. A similar group did the same exercise without the use of this support software. Interestingly, the students affective reactions to the computer mediated process were more positive than the control group, who did not have access to this technology. Final course grades were also significantly higher for those students who were exposed to the computer mediated discussion environment.

The studies of Sweeney \& Ingram (2001) and Alavi (1994) support the cognitive model of learning, which emphasises that learning is an active, constructive and goal oriented process which is enhanced by sharing and equality during discussion. Wittrock (1986) also notes that the social and cognitive goals of EL discussions stem from the group coherence that is developed, the sharing of information, the development of ideas and the provision of feedback to one another. Levinson cited in Dewar (1999) also concurs by stating that asynchronous communication may result in communication exchanges that are of much greater intellectual quality than those that take place in immediate face to face dialogue.

In another study comparing F2F and EL, Beerman (1996) hypothesised that test scores would increase in students whose lectures were augmented with computer based multimedia as it would enhance interactive learning, critical thinking and application of knowledge. Beerman compared overall test scores (average of four examinations) and final grade distributions in an introductory nutritional science course. Students were taught with traditional lectures and overheads over two years followed by another two years of instruction in which students received lectures combined with computer based multimedia (rather than overheads). Class compositions across the four years were similar and over $95 \%$ of the same examination 
questions were used across the study. The results indicate that overall means differed significantly across years when taught with and without computer mediated multimedia. Students taught with multimedia had significantly higher test scores.

Andrewartha and Wilmot (2001) also have studied the use of multimedia to augment student learning as a strategy for enhancing active learning in students. In this study they developed a multimedia course on 'editting' to replace traditional classroom based teaching on this subject. The pilot study involved two non-random groups of volunteer media arts students. Twelve students studied the course using the multimedia software whereas 20 students studied the course in a traditional classroom environment. Content was the same. Both students received a pre-test on the subject and then a post-test after completing their study. Students in the multimedia group had a pre-test score of 25 per cent and a post-test score of 62 per cent. Students in the classroom group had a pre-test score of 24 per cent and a post-test score of 38 per cent. The multimedia group improved by a much greater margin. The researchers concluded that multimedia was as good as traditional classroom instruction, if not better, because students were more actively engaged with the material.

Schutte (1996) conducted a randomised controlled study of EL versus F2F learning in a sociology unit. A class of 33 students were randomly split into two groups. Both groups were similar demographically. One group received weekly instruction in a classroom environment whereas the other group received instruction through computer mediated technology. Students in the classroom submitted weekly problem assignments. Students in the computer mediated course had weekly problem discussions, peer collaboration activities, problem assignments and weekly synchronous discussions with the lecturer. Both groups learned the same content, which was taught by the same instructor. The same midterm and final examinations were written by students in both groups. Students in the computer mediated course significantly outperformed their peers in the classroom environment on the midterm and final examination, as well as on all four question types. The researchers attribute this significant difference to the online collaboration and the sharing and networking of ideas between and amongst students.

\section{Gender issues in EL}

Gender differences in EL have also been investigated in business education as moderators of learning outcome. Arbaugh (2000) reported that men saw cyberspace and the Internet in general as a means of delivering education to the masses more quickly and at less cost. Men also tended to communicate via the medium in a competitive mode by either 
elevating their own status or by lowering others. Women, in contrast, saw cyberspace as a means to develop increased collaboration and support networks for increasing learning and communication of the group. Arbaugh's research also found that there were no gender based differences in achievement at the postgraduate level in a particular business unit. While their sample size was small, they also found that women displayed more collective and individual participation patterns than men, even though chi-square analysis revealed only moderate significant differences between the genders. They also found that the lack of F2F interaction in an asynchronous EL environment where collaboration is encouraged, does not necessarily lead to a reduction in academic achievement.

Richardson \& Turner (2000) found similar gender based findings in their study of EL. With a substantially larger sample population, they found that women were more negative towards EL. While this appears inconsistent with the results of Arbaugh (2000), in the Richardson \& Turner study women self rated as being less computer literate and found the EL environment to be lacking in collaboration. Hence, female preferences for more interactive and collaborative learning outcomes were not replicated in this study. In consequence, they support the findings of Arbaugh (2000) who noted the importance of collaboration in EL, in particular, for female students.

\section{Student centered issues}

Other studies have been directly critical of the EL experience. Hara \& Kling (1999) for example, studied the learning experience of six inexperienced computer users studying in an online environment. They found that the learners had three common frustrations: lack of prompt feedback; ambiguous instructions on the web; and technical problems. These same frustrations and problems with EL have also been noted by others in the literature (Arbaugh 2000). These researchers argue that these frustrations can have negative effects on cognition and can demotivate students considerably, which in turn reduces educational achievement. Again, rather than denigrating EL, it again raises the importance of having a strong pedagogical focus to the design of EL units and appropriate technological competence and infrastructure.

Meisel \& Marx (1999) in a review of the literature found that EL was less rich in that there was less eye contact, increased emotional detachment and a greater predilection to hold onto strongly held beliefs. In contrast they found that EL was a better facilitator of idea generation in group decision making. Jiang \& Ting (1998) conducted a study of factors that influenced students' perceived EL experience. Qualitative and quantitative methods were employed and indicated that the percentage of grade 
allocation to online discussion and the instructor's specification of requirements for student contributions in the discussion room were significantly and positively correlated to students' perceived amount of learning. Although the level of instructor participation was not significantly correlated with the students' perceived amount of learning, Jiang and Ting found it had a significant correlation with level of students participation. The results of this research again support constructivist views that students learn better through social construction of meaning, particularly where the instructor scaffolds the learning and supports students during the collaborative learning process (Wittrock 1986).

Bacani and Rohlfs (2000) noted that EL requires considerable self discipline, organisation, responsibility, support from family and friends, and perseverance. Students who elect to take an EL unit, therefore, may possess a higher degree of autonomy and motivation from their counterparts who select F2F courses. Dunlop \& Scott (2001) in a study on distance education students found that these students preferred EL significantly over the traditional paper based method. This finding has been paralleled by Richardson \& Turner (2000) who found when they evaluated task orientation and perception of EL, students who were inclined to engage with and enjoy independent learning activities had more positive perceptions of EL. Hence, there may be some intrinsic factors within students themselves, that cause them to self select F2F versus EL modes of study. This self selection, in turn, would influence their evaluations of their learning experience.

Self selection or learning styles, therefore, are another factor that may influence preferences for F2F versus EL. Halsne \& Gatta (2002) conducted a study of EL and F2F learning at the community college level. There were over 1600 respondents across these two learning examples. In addition to other demographic variables, the researchers evaluated participants' learning styles using Barsch's Learning Style Inventory. The researchers found that participants in EL were predominately visual learners and spent on average an extra hour per week on classwork in comparison to their F2F counterparts. F2F learners were predominately auditory or kinaesthetic learners. Terrell (2003) also noted the presence of learning style influences in predicting student success in web based learning environments. Their study followed 159 doctoral students majoring in computing technology in education. Kolb's Learning Style Questionnaire was the instrument used in this study. Terrell reports that students were generally able to adapt their learning style in order to succeed in a web based environment. However, students with a preference for systematic planning and abstract conceptualisation of a situation were more likely to succeed, than students preferring concrete experience and interaction with other students. 
This issue of self selection and learning style was also seen in a study by Felix (2001). In this study Felix found that students appeared to prefer the mode of study they were 'used to' rather than considering other possible solutions. In their study, distance learners expressed a preference for EL and for using materials on their own. In contrast, F2F learners were not expecting to learn electronically and expressed a desire to maintain the traditional form of teaching. This preference for learning has also been corroborated in other research (Ladyshewsky \& Nowak 2000).

To complicate the conclusions that one might glean from the research examining EL, ongoing advances are being made in technology, pedagogy, and the increasing skill base of academics and students who teach and learn, respectively, online. Research that is three to five years old is often outdated. Learning management systems continue to develop their capabilities to create virtual learning environments. Broadband technology and streaming technologies have opened up new channels for the delivery of visual and auditory information. The reliability of technology has also increased. Hence, many of the problems cited in the past that were impediments to EL are disappearing, and in some cases being replaced by other issues.

In this research, further evidence is added to the debate on the efficacy and effectiveness of EL. This study was a large scale quantitative evaluation of F2F and EL which took gender and age into consideration.

\section{Methods}

The Curtin University of Technology Graduate School of Business (GSB) made a commitment to move towards flexible learning in order to better serve the needs of its students. It was seen as a strategic initiative to support offshore students and to open up new markets, in particular, students in the oil, gas and mining industry who are based in rural Australia and who cannot attend traditional F2F classes with any regularity. The GSB was supported by funding from the University to assist the staff of the School to increase its use of flexible delivery methods. One of the strategies in this redevelopment was e-learning. A full description of this initiative is located on the Graduate School of Business website, http:/ / www.cbs.curtin.edu.au/gsb/

IBM Lotus LearningSpace is the software management system driving the EL system at the School. Student data on performance in nine units was collected for two years. The units that were evaluated were: Human Resource Strategies, Marketing Management, Competitive Marketing Strategies, Organisational Behaviour, Legal Environment, Financial Management, Economic Analysis and Asian Economies, Strategic Cost 
Management and Strategic Information Management. Data was collected for both the F2F and EL versions of these nine units. All nine units in the EL mode were considered 'fully online' as defined by Finder \& Raleigh (1998). They see a fully online unit involving no face to face interaction with all course content, assignments and communication taking place online.

All nine EL units followed the constructivist learning principles espoused by Chickering and Erhmann (1996). The same unit controllers who were responsible for the F2F versions of these units were the same individuals who moderated the design of the EL version of the unit. All unit controllers were also support by two full time EL staff and a part time educational specialist. The units in EL mode were designed using a standardised template that had been developed by the academic staff.

Within LearningSpace there are five sections that support the virtual classroom experience. These five sections are the schedule, mediacenter, courseroom, student/staff profiles and the assessment manager. The schedule is the roadmap for students and reflects the template. Within the schedule there are 12 modules (as there are 12 teaching weeks in a trimester). Within each module there are a variety of educational activities. These educational activities are similar across the nine units. In general, each module's educational activities are broken down in the following manner:

1. Overview (lecture notes, diagrams, figures, tables and illustrations)

2. Readings and Internet links (required reading in accompanying textbooks, scanned material, links to scholarly databases, links to websites)

3. Practical activities - for self assessment or for grading (quizzes, short answer/MCQ tests, web based exercises, PDF questionnaires, personal journals, case studies, group projects, etc...)

4. Discussion activity (open ended questions and exercises, case studies, problem sets). These are moderated by a lecturer and are designed to integrate material and reading from the module.

The Graduate School of Business operates on a trimester system. All 9 units were offered in different trimesters (see Table 1). Class sizes ranged from 10-40 students in EL mode and from 15-40 students in F2F mode. When enrolments in an EL unit started to approach 25, discussion rooms were split into two communities to avoid excessive duplication of comment and to keep the amount of content for the students to read at a manageable level. Computer literacy of these students was considered to be high, given earlier research on the student population at the GSB (Ladyshewsky \& Nowak 2000). 
Table 1: Availability of the units by time period

\begin{tabular}{|c|c|c|c|c|c|c|c|}
\hline \multirow{2}{*}{\multicolumn{2}{|c|}{\begin{tabular}{|c|} 
Year \\
Trimester \\
\end{tabular}}} & \multicolumn{3}{|c|}{ Year 1} & \multicolumn{3}{|c|}{ Year 2} \\
\hline & & First & Second & Third & First & Second & Third \\
\hline \multicolumn{2}{|c|}{ Study per. } & $\mathrm{T} 1$ & T2 & T3 & $\mathrm{T} 4$ & T5 & T6 \\
\hline \multirow{9}{*}{$\begin{array}{l}\text { Unit } \\
\text { code }\end{array}$} & 5282 & $\mathrm{~F} 2 \mathrm{~F}$ & $\mathrm{~F} 2 \mathrm{~F}$ & EL & EL/F2F & $\mathrm{F} 2 \mathrm{~F}$ & EL/F2F \\
\hline & 5697 & $\mathrm{~F} 2 \mathrm{~F}$ & EL & $\mathrm{F} 2 \mathrm{~F}$ & F2F & EL & $\mathrm{F} 2 \mathrm{~F}$ \\
\hline & 5698 & EL/F2F & $\mathrm{F} 2 \mathrm{~F}$ & EL/F2F & $\mathrm{EL} / \mathrm{F} 2 \mathrm{~F}$ & EL/F2F & EL/F2F \\
\hline & 5699 & F2F & EL & F2F & F2F & F2F & EL/F2F \\
\hline & 5906 & $\mathrm{~F} 2 \mathrm{~F}$ & EL & $\mathrm{N} / \mathrm{A}$ & $\mathrm{F} 2 \mathrm{~F}$ & EL & $\mathrm{N} / \mathrm{A}$ \\
\hline & 5934 & EL & EL/F2F & $\mathrm{F} 2 \mathrm{~F}$ & $\mathrm{~N} / \mathrm{A}$ & $\mathrm{N} / \mathrm{A}$ & $\mathrm{N} / \mathrm{A}$ \\
\hline & 6431 & $\mathrm{~N} / \mathrm{A}$ & EL & $\mathrm{F} 2 \mathrm{~F}$ & F2F & EL & $\mathrm{F} 2 \mathrm{~F}$ \\
\hline & 6439 & EL & $\mathrm{F} 2 \mathrm{~F}$ & EL & EL & $\mathrm{F} 2 \mathrm{~F}$ & $\mathrm{~N} / \mathrm{A}$ \\
\hline & 6649 & $\mathrm{~N} / \mathrm{A}$ & $\mathrm{F} 2 \mathrm{~F}$ & EL & $\mathrm{EL} / \mathrm{F} 2 \mathrm{~F}$ & $\mathrm{~F} 2 \mathrm{~F}$ & EL \\
\hline
\end{tabular}

The specific data that was collected on all students included: gender, age, course enrolment, unit enrolment, and final grade (percentage). Student data was obtained through the receipt of custom reports from the University Statistics Office.

\section{Data analysis}

Effect size indicators were used as measures of practical significance. The effect size indicator is a simple means analysis and is recommended in research situations where one group of subjects receives a given intervention (EL), and another group does not receive this intervention (F2F) (Glass, McGraw \& Smith, 1981; Nelson, 1981).The effect size method evaluates the difference between the means of pairs of treatment conditions and is best divided by the composite group standard deviation thus yielding a standardised mean difference (Albanese \& Mitchell, 1993).

Vockell and Asher (1995) note that the ESI is basically a z-score. These zscores range from -3.00 to +3.00 . Hence, the degree to which the average subject in the experimental group is better or worse off than the average control subject can be examined on a percentile basis. For example, an effect size of .35 means that the experimental group scored .35 standard deviations above the control group in the study under consideration (Vockell \& Asher, 1995). Cohen (1969) classifies effect sizes as small (.20), medium (.50) and large $(\geq .80)$.

The t-test is an inferential test that measures whether random sampling alone is the reason for group differences (Nelson, 1981). These tests are 
carried out where practical significance is noted and the investigator is interested in ruling out the possibility that chance alone is the reason for the experimental effects. The analysis of variance test was applied to those students who experienced both EL and F2F as part of their course of study. The analysis of variance examines the significance of the differences among two or more groups.(Vockell \& Asher, 1995).

\section{Results}

Table 2 provides information on enrolments across all nine units by EL and F2F categories. The majority of students studied in the face to face environment (77.5 per cent).

Table 2: Enrolments: Total, e-learning and face to face

\begin{tabular}{|c|c|c|c|c|c|}
\hline \multirow{2}{*}{ Units } & \multirow{2}{*}{ All } & \multicolumn{2}{|c|}{ EL } & \multicolumn{2}{c|}{ F2F } \\
\cline { 3 - 6 } & & $\mathrm{N}$ & $\%$ & $\mathrm{~N}$ & $\%$ \\
\hline All & $\mathbf{1 4 0 1}$ & $\mathbf{3 1 6}$ & $\mathbf{2 2 . 5}$ & $\mathbf{1 0 8 5}$ & $\mathbf{7 7 . 5}$ \\
\hline 5282 & 218 & 27 & 12.4 & 191 & 87.6 \\
\hline 5697 & 182 & 29 & 15.9 & 153 & 84.1 \\
\hline 5698 & 289 & 48 & 16.6 & 241 & 83.4 \\
\hline 5699 & 236 & 50 & 21.2 & 186 & 78.8 \\
\hline 5906 & 90 & 24 & 26.7 & 66 & 73.3 \\
\hline 5934 & 36 & 16 & 44.4 & 20 & 55.6 \\
\hline 6431 & 163 & 68 & 41.7 & 95 & 58.3 \\
\hline 6439 & 80 & 26 & 32.5 & 54 & 67.5 \\
\hline 6649 & 107 & 28 & 26.2 & 79 & 73.8 \\
\hline
\end{tabular}

Table 3 provides information on enrolment by gender across all units by EL and F2F categories. Males represented, on average, just over two thirds of the total enrolment (68 per cent). This same pattern was reflected, to a slightly greater or lesser degree, in each of the units.

Table 3: Enrolments by gender: Total, e-learning and face to face

\begin{tabular}{|c|c|c|c|c|c|c|c|c|c|c|c|c|}
\hline Units & \multicolumn{4}{|c|}{ All } & \multicolumn{4}{|c|}{ EL } & \multicolumn{4}{|c|}{ F2F } \\
\hline & $\mathrm{M}$ & $\%$ & $\mathrm{~F}$ & $\%$ & $\mathrm{M}$ & $\%$ & $\mathrm{~F}$ & $\%$ & $\mathrm{M}$ & $\%$ & $\mathrm{~F}$ & $\%$ \\
\hline All & 953 & 68 & 448 & 40 & 206 & 65.2 & 110 & 34.8 & 747 & 68.8 & 338 & 31.2 \\
\hline
\end{tabular}

Table 4 provides information on enrolment by age across all units by EL and F2F categories. The breakdown is for students under 33 years of age and those 33 and older.

Table 4: Enrolments by age: Total, e-learning and face to face

\begin{tabular}{|c|c|c|c|c|c|c|c|c|c|c|c|c|}
\hline Units & \multicolumn{4}{|c|}{ All } & \multicolumn{4}{|c|}{ EL } & \multicolumn{4}{c|}{ F2F } \\
\hline & -33 & $\%$ & +33 & $\%$ & -33 & $\%$ & +33 & $\%$ & -33 & $\%$ & +33 & $\%$ \\
\hline All & 719 & 51.3 & 682 & 49.7 & 157 & 49.7 & 159 & 50.3 & 562 & 51.8 & 523 & 48.2 \\
\hline
\end{tabular}


Table 5 provides details as to whether or not there were any differences in student performance across the two modes of learning. When taking the average of all student grades across all nine units, students in the EL mode did significantly better. The effect size indicator of 0.1068 suggests small practical significance. At the individual unit level, most units demonstrated no significant difference in either learning mode. There were two exceptions. In unit 5697 students did significantly better in the EL mode with an effect size indicator of 0.505 suggesting moderate practical significance. In unit 6431 students did significantly poorer in the EL mode with an effective size indicator -0.3850 , which is of moderate practical significance.

Table 5: Differences in e-learning versus face to face

\begin{tabular}{|c|c|c|c|c|c|}
\hline Unit code & ESI & t-value & $\begin{array}{c}\text { Degrees of } \\
\text { freedom }\end{array}$ & P-value & Significance \\
\hline All units & 0.1068 & 2.4142 & 1399 & 0.0161 & ${ }^{* *}$ \\
\hline 5282 & -0.0725 & -0.5806 & 216 & 0.5645 & NS \\
\hline 5697 & 0.505 & 4.1744 & 180 & 0.0001 & $* * *$ \\
\hline 5698 & 0.0105 & 0.0939 & 287 & 0.9252 & NS \\
\hline 5699 & 0.1612 & -1.4787 & 234 & 0.1406 & NS \\
\hline 5906 & 0.2791 & 1.5866 & 88 & 0.1162 & NS \\
\hline 5934 & -0.2432 & -1.0524 & 34 & 0.3001 & NS \\
\hline 6431 & -0.3850 & -3.4704 & 161 & 0.0007 & ${ }^{* * *}$ \\
\hline 6439 & -0.1039 & -0.5661 & 78 & 0.5752 & NS \\
\hline 6649 & 0.2454 & 1.6369 & 105 & 0.1046 & NS \\
\hline
\end{tabular}

$\left.{ }^{* *}\right)$ significant at $5 \%$ level, $\left({ }^{* * *}\right)$ significant at $1 \%$ level and (NS) means not significant

There did not appear to be any noteworthy differences in academic achievement across the EL and F2F modes by gender. Similarly, there were no significant differences in academic achievement across EL and F2F mediums for individuals 33 years of age and older. There were, however, significant differences across the EL and F2F mediums for students under 33 years of age, which are depicted in Table 6. On average, students under 33 years of age did significantly better in the EL mode when all nine units were taken into consideration. The effect size indicator of 0.1847 , in this example, is of small practical significance. This pattern was seen in two of the other units of study, 5697 and 5906, which had moderate and strong measures of practical significance as suggested by their effect size indicators of 0.4797 and 0.6047 respectively. Students under 33 years of age did significantly poorer in the EL mode in unit 6431 with a moderate effect size indicator of -0.3583 .

For students who experienced both EL and F2F mediums as part of their study $(n=138)$, an analysis of variance was carried out to determine if their 
performance differed across these two mediums. There were significant differences $(\mathrm{F}=7.7, \mathrm{df}=1, \mathrm{df}=334, \mathrm{P}$-value $=0.006)$ in the students performance between the two modes of study at the one percent level of significance, with the average score for the EL medium being significantly higher.

Table 6: Comparisons of scores for EL and F2F for students under 33 years of age

\begin{tabular}{|c|c|c|c|c|c|}
\hline Unitcode & ESI & t-value & $\begin{array}{c}\text { Deg. of } \\
\text { freedom }\end{array}$ & P-value & Sig. \\
\hline All units & $\mathbf{0 . 1 8 4 7}$ & $\mathbf{3 . 1 0 2 8}$ & $\mathbf{7 1 7}$ & $\mathbf{0 . 0 0 2 1}$ & ${ }^{* * *}$ \\
\hline 5282 & 0.0745 & 0.496 & 111 & 0.6233 & NS \\
\hline 5697 & 0.4797 & 2.5228 & 100 & 0.0132 & ${ }^{* *}$ \\
\hline 5698 & -0.0825 & -0.5361 & 139 & 0.5927 & NS \\
\hline 5699 & -0.0394 & -0.2266 & 120 & 0.8212 & NS \\
\hline 5906 & 0.6047 & 2.8907 & 42 & 0.0066 & ${ }^{* * *}$ \\
\hline 5934 & -0.2906 & -0.8629 & 16 & 0.4009 & NS \\
\hline 6431 & -0.3583 & -2.3232 & 82 & 0.0226 & ${ }^{* *}$ \\
\hline 6439 & 0.0775 & 0.3643 & 43 & 0.7175 & NS \\
\hline 6649 & 0.4767 & 1.9657 & 48 & 0.0551 & NS \\
\hline
\end{tabular}

$\left.{ }^{* *}\right)$ significant at $5 \%$ level, $\left.{ }^{* * *}\right)$ significant at $1 \%$ level and (NS) means not

significant

The remaining analysis of this study examined the "evolution" of the EL medium. This analysis was carried out to see if there were any trends in average student performance over time. The possibility of students doing better, because staff became better at the design, delivery and underlying pedagogy of their EL units over time, was the central question. Table 7 illustrates the study periods for the two years with trimesters indicated sequentially from $\mathrm{T} 1$ to $\mathrm{T} 6$

Overall, student performance in the EL units, on average, significantly improved over the course of the 6 study periods as illustrated in Table 7 , suggesting an improvement in overall staff competency with respect to design and delivery of EL units. However, at the unit level, there were no statistically significant differences over time with the exception of one unit, 5906, in which student performance increased significantly over time.

\section{Discussion}

This research provides some assurance that well designed EL initiatives can deliver quality academic outcomes. By focussing on the pedagogy behind unit design and delivery, the academic program in this research study was able to design and deliver EL units that produced a high quality outcome. This outcome was contingent on avoiding the tendency to merely post information on the web, which is a common occurrence in the 
EL marketplace (Mioduser, Nachmias, Lahav \& Orens 2000). Instead, a responsive and creative learning environment was designed in keeping with the principles espoused by Chickering and Erhmann (1996). This was achieved by ensuring high quality regular contact between students and instructor through emails and the discussion rooms. Further, active learning strategies such as self assessments, practical activities and project based assignments assisted in the engagement of students.

Table 7: Differences in average student performance over the study period

\begin{tabular}{|c|c|c|c|c|}
\hline UnitCode & F-value & $\begin{array}{c}\text { Deg of freedom } \\
\text { Df1, Df2 }\end{array}$ & P-value & Significance \\
\hline All Units & 2.5767 & 5,310 & 0.0265 & ${ }^{* *}$ \\
\hline 5282 & 1.5739 & 2,24 & 0.2278 & NS \\
\hline 5697 & 0.0481 & 1,27 & 0.828 & NS \\
\hline 5698 & 2.32 & 4,43 & 0.0721 & NS \\
\hline 5699 & 0.0184 & 1,48 & 0.8924 & NS \\
\hline 5906 & 5.4551 & 1,22 & 0.029 & ${ }^{* *}$ \\
\hline 5934 & 1.1018 & 1,14 & 0.3116 & NS \\
\hline 6431 & 1.1268 & 1,66 & 0.2923 & NS \\
\hline 6439 & 0.5972 & 2,23 & 0.5586 & NS \\
\hline 6649 & 0.8181 & 2,25 & 0.4526 & NS \\
\hline
\end{tabular}

$\left.{ }^{(* *}\right)$ significant at 5\% level, (NS) means not significant.

Expectations for student performance were highly transparent with detailed instructions and timelines provided for all online activities and exercises. Considerable attention was also paid to the alignment between online activities, responsibilities and unit assessment. A help desk was also available to assist students with any of the technical aspects associated with online study. Many of the initiatives mentioned above were put into place to avoid some of the problems noted by students in the literature who have been frustrated with EL, namely: lack of prompt feedback; ambiguous instructions on the web; and technical problems.(Arbaugh 2000; Hara \& Kling 1999) Elimination of these problems ensures students are highly motivated and engaged with their study, rather than being frustrated and anxious about the quality of the EL unit.

It was assuring to see that overall, students in the EL units did significantly better on average than their counterparts in the F2F environment. This was in keeping with other research comparing EL to F2F learning (Alavi 1994; Beerman 1996; Andrewartha \& Wilmot 2001; Schutte1996). At the individual unit level, however, differences in academic performance across the two modes of learning were insignificant. When examining the ESI results by unit, it was clear that some students, on average, did better in the EL mode whereas in other cases, unit performance was better in F2F mode. In one unit, students did 
significantly better in the EL mode and in another unit, students did significantly poorer in the EL mode. The differences across all nine units appear to balance each other out when an overall measure of academic performance is taken. A useful conclusion, looking at the results this way, is that students generally do well in both modes of study. This conclusion is consistent with good quality research in this area (Brennan, McFadden \& Law 2001).

Keeping EL discussion rooms manageable with respect to size was perhaps another factor that ensured a positive educational outcome. For example, when student enrolments within an EL unit approached 20 or more, discussion rooms were then split into smaller groups of approximately 10-15 students and managed separately by the instructor. Arbaugh (2000) noted that class size was an important factor in the success of EL as smaller, more manageable groups appear to facilitate integration and the development of a learning community.

Gender did not appear to have any influence on academic performance across the two modes of learning, which is consistent with earlier research by Arbaugh (2000). Age also did not appear to be a factor in performance across the two modes of learning for students 33 years of age and older. This was not the case for students under 33 years of age. These students did significantly better, on average, in the EL mode even though the difference is of small practical significance. At the unit level some students, on average, did better in the EL mode whereas other students did better, on average, in the F2F mode. A useful conclusion looking at the results this way is that students do well across both modes of study but in this age group, EL provided a slight advantage. Arbaugh (2000) suggested that computer literacy was an important determinant of a student's EL experience and frustrations with using technology could reduce motivation and performance of the learner. Learners under 33 years of age typically represent the generation that are more computer literate and competent. This may have had an effect on their greater performance in the EL mode.

Perhaps the most interesting outcome from this research was the academic achievement of students who had taken units in both the EL and F2F mode. At this level of analysis a greater sense of control is achieved because you have the same person experiencing two different modes of learning. What was interesting in this situation was that these students' grades were significantly better in the EL mode. It is not possible from this research to determine if there was a self selection factor in operation, or whether it was truly the design and experience of the EL experience that engaged the students in such a way that their learning was enhanced. 
Self selection issues identified by Halsne \& Gatta (2002) and Felix (2001) may explain some of the differences in this study, particularly if distance students and those with a preference for individualistic and visual forms of learning opted for the EL mode (Richardson \& Turner 2000) As noted by Bacani \& Rohlfs (2000) and Dunlop \& Scott (2001), EL requires considerable self discipline, and students who elect to take an EL unit, may possess a higher degree of autonomy and motivation. This may have been a small factor in the favorable outcomes seen for EL. For example, student enrolments in the EL mode typically represent students who are not in the Perth Metropolitan region or who cannot physically attend F2F classes. The commitment to pursue higher education under these circumstances may indicate a higher degree of motivation in these learners, which could have an impact on their final grades.

As noted earlier, the average performance of students in the EL mode, increased significantly over time, as staff became more competent at delivering education on line. At the unit level, however, any differences in average student performance over time was insignificant. Hence, developing staff competency in EL did not appear to be a major factor that might have influenced the scores of students improving over time. Differences measured, therefore, appear to relate to differences in the two modes of educational delivery.

\section{Assumptions and limitations}

Some of the assumptions and limitations of this study also need to be qualified. It was assumed that students undertaking study in either the EL or F2F mediums were equally competent. The close team work of the staff also ensured that there was a similar structure and level of quality across the units. All units were designed keeping in mind the principles espoused by Chickering and Erhmann (1996). Having the same unit controllers who developed the F2F version of the unit, also creating the EL unit, was another methodological advantage.

Student grades may also not represent the best indicator to evaluate student performance (Sweeney \& Ingram 2001). A single measure of learning may not completely capture the content and quality of student learning (Arbaugh 2000). Other measures, such as student learning preferences, learning history and adaptability to new technology are obviously other moderating factors that have an impact on EL and F2F outcomes. Since learning is such a multi-dimensional issue, it has even been argued that perhaps quantitative methods may be inappropriate and that qualitative studies which look at the relationships between EL and training, student outcomes and social constructions of meaning are more appropriate (Brennan, McFadden \& Law 2001; Treleaven 2003). In arguing 
against these comments, however, it is still useful to look at other measures to gain a complete picture of differences in student performance across F2F and EL modes. Academic outcomes are one part of the entire picture.

One limitation of this research is that the nine units are different from one another in terms of their content, and the subtle differences in delivery and assessment. Even though units were delivered using a standard template and structure, these variances cannot be ignored as influences moderating student performance. The amount of individual work is generally greater in the EL mode. Group work is used more considerably in the F2F versions of the same unit. Instructors also differ within and between the units. Tutors of an EL unit may not necessarily be the same person who delivers the F2F unit. These are all factors that have an influence on the study's outcomes.

There was also a large difference in the number of students who undertook the two mediums of learning. Face to face participants are the larger sample group in comparison to the EL group and this may have had an influence on the power of the statistical analyses.

\section{Conclusions}

This research provides some assurance that student performance is at least as good as, if not slightly better, in EL mode when compared to F2F delivery. This finding is consistent with other studies that have reported differences in learning outcome between F2F and EL delivery modes. When a high degree of pedagogical thought goes into the design and delivery of EL, and is supported by adequate resources, positive educational outcomes can be achieved by students. Quantitative and qualitative research studies that look at traditional as well as nontraditional measures of student performance, are still needed to increase our understanding of learning outcomes in electronic mediums.

\section{References}

Alavi, M. (1994). Computer-mediated collaborative learning: An empirical evaluation. MIS Quarterly, 18(2), 159.

Albanese, M. \& Mitchell, S. (1993). Problem based learning: A review of literature on its outcomes and implementation. Academic Medicine, 68(1), 52-81.

Allen, M. (1999). Don't be a troll! Using the Internet for successful higher education. Higher Education, Sydney. 
Andrewartha, G. \& Wilmot, S. (2001). Can multimedia meet tertiary educational needs better than the conventional lecture? A case study. Australian Journal of Educational Technology, 17(1), 1-20.

http: / / www.ascilite.org.au/ajet/ajet17/andrewartha.html

Arbaugh, J. (2000). An exploratory study of the effects of gender on student learning and class participation in an Internet-based MBA course. Management Learning, 31(4), 503-519.

Bacani, C. \& Rohlfs, O. (2000). Click here for a diploma. Asiaweek, 22 June. [viewed 26 Sep 2003, verified 11 Jul 2004]

http://www.asiaweek.com/asiaweek/features/universities2000/artic_online.html

Beerman, K. A. (1996). Computer-based multimedia: New directions in teaching and learning. Journal of Nutritional Education, 28(1), 15-18.

Berger, N. (1999). Pioneering experiences in distance learning: Lessons learned. Journal of Management Education, 23(6), 684-690.

Brennan, R., McFadden, M. \& Law, E. (2001). Review of research: All that glitters is not gold: online delivery of education and training, Australian National Training Authority. Leabrook, South Australia: NCVER.

Bull, K. S., Kimball, S. \& Stansberry, S. (1998). Techniques for developing a syllabus / website for a computer mediated learning (CML) course. Proceedings of the American Council on Rural Education, Charleston, March. Available [ERIC] (April 11, 2003).

Chickering, A. \& Ehrmann, S. (1996). Implementing the Seven Principles: Technology as lever. American Association for Higher Education Bulletin. October, pp.3-6.

Cohen, J. (1969). Statistical Power Analysis for the Behavioural Sciences, New York, Academic Press.

Dewar, T. (1999). Adult Learning Online. [viewed 6 Apr 2000 at http: / / www.telusplanet.net/public/tddewar/low98/mod2.htm, verified 12 Jul 2004 at http: / / www.calliopelearning.com/adult.htm]

Dunlop, M. \& Scott, D. (2001). An examination of the impact of aspects of online education delivery on students. Proceedings AusWeb. http: / / ausweb.scu.edu.au/aw01/ papers/ refereed/dunlop/ paper.html

Felix, U. (2001). A multivariate analysis of students' experience of web based learning. Australian Journal of Educational Technology, 17(1). 21-36. http: / / www.ascilite.org.au/ajet/ajet17/ felix.html

Finder, K. \& Raleigh, D. (1998). Establishing a framework useful for developing web-based assignments in K-12 education. Proceedings of the Society for Information Technology and Teacher Education Conference. 
Glass, G., McGaw, B. \& Smith, M. (1981). Meta-analysis in Social Research, London, Sage Publications.

Halsne, A. \& Gatta, L (2002). Online versus traditionally-delivered instruction: A descriptive study of learner characteristics in a community college setting. Online Journal of Distance Learning Administration, 5(1). [viewed 17 Apr 2003, verified 12 Jul 2004]

http:/ / www.westga.edu/ distance/ojdla/spring51/halsne51

Hara, N. \& Kling, R. (1999). Students' frustrations with a Web-based distance education course: A taboo topic in the discourse. CSI Working Paper No. WP 9901-C1. [viewed 15 Apr 2003, verified 12 Jul 2004]

http: / / www.slis.indiana.edu /CSI/ wp99_01.html

Hiltz, R. (1986). The virtual classroom: Using computer-mediated communication for university teaching. Journal of Communication, 36(2), 95-104.

Jasinski, M. (1998). Teaching and learning styles that facilitate on line learning: Documentation project, project report, Adelaide, Douglas Mawson Institute of TAFE.

Jiang, M. \& Ting, E. (1998). Course Design, Instruction, and Students' Online Behaviors: A Study of Instructional Variables and Students' Perceptions of Online Learning. Paper presented at the Annual Meeting of the American Educational Research Association, April 13-17. San Diego, CA.

Ladyshewsky, R. \& Nowak, M. (2000). Postgraduate business education and flexible learning strategies: An analysis of customer perspective. In M. Kulski \& A. Herrmann (Eds.), New horizons in university teaching and learning: Responding to change. Perth, Australia: Curtin University Press.

McGrath, C. (1997-98). A new voice on interchange: Is it talking or writing? Implications for the teaching of literature. Journal of Educational Technology Systems, 26, 291-297.

McLoughlin, C. (2000). Beyond the halo effect: Investigating the quality of student learning online. Proceedings Moving Online Conference, School of Social Sciences, Southern Cross University. [viewed 12 Apr 2003 at

http:/ / www.scu.edu.au/schools/sawd/moconf/mocpapers/moc16.pdf,

verified $12 \mathrm{Jul} 2004$ at downloads menu

http: / / www.scu.edu.au/schools/ socialsciences/dds/?menu=95]

Meisel, S. \& Marx, B. (1999). Screen to screen versus face to face: Experiencing the differences in management education. Journal of Management Education, 23(6), 719-731.

Mioduser, D., Nachmias, R., Lahav, O. \& Oren, A. (2000). Web-based learning environments: Current pedagogical and technological state. Journal of Research on Computing in Education, 33(1), 55-76. 
Nelson, L. (1981). Platisla: An Introduction to Applied Social Science Statistical Methods. Dunedin, University of Otago.

Richardson, J. A. \& Turner, A. (2000). A large-scale 'local' evaluation of students' learning experiences using virtual learning environments. Educational Technology and Society, 3(4), 108-125. [verified 11 Jul 2004] http:/ / ifets.ieee.org/periodical/vol_4_2000/richardson.html

Schutte, J. G. (1996). Virtual teaching in higher education: The new intellectual super-highway or just another traffic jam? [verified 18 Feb 2004] http: / / www.csun.edu/ sociology/ virexp.htm

Sweeney, J. \& Ingram, D. (2001). A comparison of traditional and web-based tutorials in marketing education: An exploratory study. Journal of Marketing Education, 23(1), 55-62.

Terrell, S. (2003). The effect of learning style on doctoral course completion in a Web-based learning environment. The Internet and Higher Education, 5(4), 345352.

Treleaven, L. (2003). A new taxonomy for evaluation studies of online collaborative learning. In T. Roberts (Ed), Online Collaborative Learning. Queensland: Information Science Publishing. pp. 160-180.

Vockell, E. \& Asher, J. (1995). Educational Research, 2nd ed. Englewood-Cliffs, New Jersey: Prentice-Hall Inc.

Volery, T. \& Lord, D. (1999). Reforming universities' teaching practices: Critical success factors for the use of the Internet. Paper presented at Reforming the Universities for the 21st Century conference. Beijing, China.

Wittrock, M. C. (1986). Students' Thought Processes. In M. C. Wittrock (Ed), Handbook of Research on Teaching, 3rd ed. New York, Macmillan, pp. 297-314

This article is an expanded and revised version of a previously published article. Ladyshewsky, R. K. (2004). Online learning versus face to face learning: What is the difference? In Seeking Educational Excellence.

Proceedings of the 13th Annual Teaching and learning Forum, 9-10

February 2004. Perth: Murdoch University.

http:/ / lsn.curtin.edu.au/tlf/tlf2004/ladyshewsky.html

Dr Richard K. Ladyshewsky is a Senior Lecturer in the Graduate Schoo of Business, Curtin University of Technology, GPO Box U1987, Perth

Western Australia 6845. Email: ladysher@gsb.curtin.edu.au Web: http:/ / www.gsb.curtin.edu.au/ 